\title{
Influence of Graduate Speech Language Pathology Student's Learning Style and Coping Strategies on Training and Development
}

\author{
Sarah Rapillard \\ sarahwrapillard@gmail.com \\ Laura W. Plexico \\ Auburn University, Iwp0002@auburn.edu \\ Allison M. Plumb \\ Auburn University, amp0016@auburn.edu \\ DOI: https://doi.org/10.30707/TLCSD3.1Rapillard
}

Follow this and additional works at: https://ir.library.illinoisstate.edu/tlcsd

Part of the Speech Pathology and Audiology Commons

\section{Recommended Citation \\ Rapillard, Sarah; Plexico, Laura W.; and Plumb, Allison M. (2019) "Influence of Graduate Speech Language Pathology Student's Learning Style and Coping Strategies on Training and Development," Teaching and Learning in Communication Sciences \& Disorders: Vol. 3: Iss. 1, Article 2. \\ DOI: https://doi.org/10.30707/TLCSD3.1Rapillard \\ Available at: https://ir.library.illinoisstate.edu/tlcsd/vol3/iss1/2}

This Scholarship of Teaching and Learning Research is brought to you for free and open access by ISU ReD: Research and eData. It has been accepted for inclusion in Teaching and Learning in Communication Sciences \& Disorders by an authorized editor of ISU ReD: Research and eData. For more information, please contact ISUReD@ilstu.edu. 


\title{
Influence of Graduate Speech Language Pathology Student's Learning Style and Coping Strategies on Training and Development
}

\begin{abstract}
A hierarchical model using grounded theory analysis was used to investigate clinical development of speech-language pathology graduate students. Eight female students attending a graduate speechlanguage pathology program participated in interviews prior to beginning graduate training and after each of five subsequent semesters. The interviews were then qualitatively analyzed to create the model of clinical development. This is the first of two companion papers and summarizes two of the five main findings identified. These findings indicated that both stress and the coping strategies used by students influenced clinical abilities and the student's feelings of self-efficacy throughout graduate training. The results support that learning theory, motivation theory, and understanding of student coping strategies could better promote clinical development and these factors in combination can be used to explain how students progress successfully through a graduate training program. The companion paper describes the remaining three findings that emphasize characteristics associated with the supervision and clinical experiences of graduate students.
\end{abstract}

\section{Keywords}

Learning Styles, Coping, Generational Differences 


\section{Introduction}

According to the American Speech-Language-Hearing Association (ASHA, 2015), the general steps required to complete the professional development process for becoming a certified speechlanguage pathologist (SLP) are clearly outlined. The anticipated outcome from completion of this detailed process is competent therapeutic abilities; however, the process of professional development and the product that results following the conclusion of graduate training is very complex and varied. How students learn and cope with the stresses of this process may impact their development and therapeutic performance. Factors that contribute to optimal student growth and development of SLPs in training remains under investigated and are poorly understood at this time. Generational differences, student learning styles, motivation, and student coping are some possible factors to consider when evaluating student development.

Generational Differences and Learning Styles. Generational differences and how they interface with learning theory requires consideration when examining the academic and clinical development of an SLP student. Understanding generational differences has the potential to decrease generational biases within the classroom and clinic as well as increase positive learning experiences (Roberts, Newman, \& Schwartzstein, 2012). According to Howe and Strauss (2000), a generation is a group of individuals that share a past, present, and future location in history that spans from childhood to adulthood. Starting in about year 2000, the generation most likely to be encountered during clinical education included students from the millennial generation: those individuals born between the years of 1982 and 2002. This group of students will continue to be encountered in clinical education until about year 2030.

Millennials can be characterized by several distinguishing traits (Howe \& Strauss, 2000). Often, millennials are characterized as confident rule followers that favor the placement of rules in the classroom as well as in society (Howe \& Strauss, 2000). They are a technologically fluent and networked culture where computers and cell phones are omnipresent, and they live in public by using social media to make connections without constraint (McCasland, 2005). Much of the millennials' learning style comes from their preference for rules, organization, and structure. For this reason, millennial learners prefer teacher-facilitated, group processes, with practical knowledge that is provided within a clear organizational structure (e.g., rubrics) (Lancaster \& Stillman, 2002).

Theories of learning can be used to identify patterns of how people acquire new information or skills and to better understand the process of how students, in this case millennial students, become independent and critical thinkers. Learning can be approached through cognitive, affective, and metacognitive processes (Short \& Weissberg-Benchell, 1989; Vermunt, 1996). When students approach learning as a cognitive process they are thinking about the material in terms of knowledge, understanding, and skill acquisition. They are approaching the material in a concrete manner, looking for relationships and looking for direct applications. Learning as an affective process occurs when a student is coping with or managing the feelings that might arise during the learning process. The affective component of learning has a direct connection to a student's level of motivation and attribution of causal factors to learning outcomes. The metacognitive process of learning refers to the regulatory aspects of the learning process, such as the student's orientation, 
self-monitoring ability, adjustment, and ability to accurately evaluate learning scenarios when difficulties arise (Vermunt, 1996).

In addition to understanding how students learn, a student's learning cycle also requires consideration in clinical teaching as it impacts a student's ability to fully understand and apply novel information. David Kolb's (2004) experiential learning style model is a well-recognized model for how students experientially acquire information. Kolb's model stands apart from other models of learning in that it accommodates the incorporation of personal change and development by recognizing the experiential aspects of the learning process and not only static learning traits (Turesky \& Gallegher, 2011). The model consists of four modes of learning and four learning styles. The four modes of learning reflect how the learner takes in, construes, and acts on information. The four learning modes are concrete experience (CE), reflective observation (RO), abstract conceptualization (RC), and active experimentation (AE). These modes of learning anchor each pole of the quadrant. The four quadrants are placed on two dimensions, which are perceiving and processing. The perceiving dimension describes how the learner prefers to take in novel information and ranges from $\mathrm{CE}$ to $\mathrm{AC}$. The processing portion describes how the learner construes information and acts on his or her environment, which ranges from AE to RO. A person's learning style results from the combination of the two independent dimensions (Kolb \& Kolb, 2005). The four learning styles form a quadrant and are accommodators, convergers, assimilators, and divergers.

According to Kolb's model (Kolb \& Kolb, 2005) accommodators are learners who are needing to be involved with the material to learn it; they are activists. They use both CE and AE to learn and process information. Accommodators have been found to make decisions more on intuition, to like goal setting, and to prefer teamwork. Convergers are learners who are in the practical application stage of learning and use $\mathrm{AC}$ and $\mathrm{AE}$ to acquire knowledge. Convergers prefer to engage in firsthand experimentation and like to find practical applications for newly acquired information. They are pragmatists who are in the technical stages of learning. Assimilators are using AC and RO to learn new information. They are theorizing and enjoy generating new ideas. These individuals are also planners and organizers and will readily read and engage in inductive reasoning. Divergers, on the other hand, are learners who gain information and learn through CE and RO. They are reflective learners. They tend to look at information from multiple perspectives, are creative, and have good communication skills. The ability to learn deeply or be flexible is heavily influenced by learning experiences provided and the overall learning process. To experience learning the student must also be open and motivated to learn in the here and now and willing to learn from his or her experiences (Kolb \& Kolb, 2005).

Motivation to Learn and Coping. Students entering healthcare professions like speech-language pathology, regardless of learning style, are generally regarded as highly motivated individuals who have an intrinsic desire to care for the clients they are serving in some capacity. That is, the students we teach tend to enter our programs with some degree of agency to want, learn, apply, and master the new skills required to be successful speech-language pathologists. Self-determination theory (SDT) can be used to understand and explore student motivation and self-regulated learning. It accounts for different types of motivation including intrinsic and extrinsic. Intrinsic motivation involves engaging in an activity because the activity or behavior itself is naturally satisfying and results in positive feelings, whereas extrinsic motivation involves engaging in an activity because 
it leads to a particular consequence that results in a tangible reward or punishment. Organismic integration theory (OIT) addresses the causes and consequences of extrinsic motivation (Deci \& Ryan, 1985). According to Deci and Ryan (1985), OIT includes four regulation steps that an individual must progress from externally to internally motivated to complete tasks. The steps include: external regulation, introjected regulation, identified regulation, and integrated regulation (Deci \& Ryan, 1985). On one end of the continuum, an externally regulated person is driven predominately by external contingencies. Introjected regulation is marked by behaviors that are driven by a desire to maintain feelings of self-worth or avoid feelings of disapproval, thereby making it driven by an internal versus external form of contingency. Identified regulation becomes evident when the learner identifies with or begins to value the behaviors he or she is engaging in. When regulation is integrated there is a high degree of autonomy and self-endorsement on the part of the learner. SDT indicates that individuals are driven by three basic psychological needs and the process of internalization and integration (Deci \& Ryan, 1985). The three psychological needs are autonomy, competence, and the need to relate to others. These three needs are essential for a person to optimally function, integrate, and maintain personal well-being. Internalization and integration is the process by which non-intrinsically or extrinsically motivated behaviors become self-determined. It is the natural process of moving from externally regulated behavior to having autonomy in self-regulation through the identification of motives, internalization of habits and volitional persistence (Deci \& Ryan, 1985).

SDT has been applied in both educational and healthcare settings to understand both relationships and behaviors. In both settings there is an emphasis on using an autonomy-supportive teaching approach by fostering an internal locus of control, free will, and opportunities for choice to encourage the acceptance of personal responsibility (ten Cate, Kusurkar, \& Williams, 2011; Reeve, 2002). In clinical training settings, the importance of type of feedback and entrusting students with delivering clinical instruction in the process of developing self-sufficiency and independence has been explored and emphasized (ten Cate et.al, 2011). Research on learning using SDT has demonstrated that positive outcomes and increased well-being are associated with the promotion of greater student autonomy and intrinsic self-regulation (Ryan \& Deci, 2000).

However, there are times when students find it difficult to grow and accept personal responsibility. That is, there are some students who have a very apathetic, mechanized, and passive approach to the learning process. A student's overall well-being affects his or her motivation. Lower motivation leads to ambiguity and can lead to personal difficulties whereas higher motivation can lead to a greater since of purpose, agency and passion for one's work (Brackney \& Karabenick, 1995). Students are faced with several stressors in graduate school. Students are expected to perform well both in the classroom and clinic and be prepared for both learning environments. Achieving a work life balance is a struggle and burn out is a risk for many students. Depression, anxiety as well as many other mental health-related conditions are becoming increasingly prevalent among students entering higher education. Environmental and personal stress as well as amotivation are factors that require consideration and have been implicated as both causes and consequences of student distress (Dyrbye, Thomas, \& Shanafelt, 2005).

Stress has been defined as, "the nonspecific response of the body to any demand," (Selye, 1956, p.1). Demand refers to the environmental influence that causes the stress reaction and is variable across individuals (Lazarus \& Folkman, 1984). According to Miller, Smith, and Rothstein (1993) 
there are two common forms of stress: acute stress and chronic stress. Chronic stress is a form of long-term stress that has been found to cause lasting physical and psychological distress. Acute stress, on the other hand, is a short-term form of stress that doesn't cause the long-term effects that are often associated with chronic stress (Miller, Smith, \& Rothstein, 1993). Stresses associated with graduate school are experienced in the short-term and can include situations such as a week where there are many assignments that are due or a time when there are many personal and school related scheduling conflicts occurring. Often, students are very aware of acute stressors, and therefore, can cope accordingly.

According to Lazarus and Folkman (1984), coping can be categorized as either problem-focused or emotion-focused. Problem-focused (PF) coping involves trying to rectify the problem causing the stress response. This type of problem solving involves defining the stressor, creating solutions, weighing costs and benefits of solutions, selecting a solution, and following through with the selected solution. Emotion-focused (EF) coping, on the other hand, involves the individual trying to stabilize his or her emotional response to the stressor (Lazarus \& Folkman, 1984). While coping is often categorized in this manner it should be noted that coping is a multidimensional interrelated process. That is, when faced with a stressor one does not necessarily cope with either PF or EF efforts. It is possible to use both forms of coping in conjunction with one another. Sources of stress in graduate students have been documented in a few studies. Results indicate that the majority of stressors involve academic achievement abilities (Coburn \& Jovaisas, 1975; Heins, Fahey, \& Leiden, 1984). Hudson and O'Regan (1994) completed a study that suggests that one particular variable cannot predict stress levels in graduate students; however, the level of support received outside of the classroom may alleviate stress. In this way, it appears that the academic and clinical learning experiences and environment of the student can influence student well-being and thus could have an impact on his or her academic and clinical development. The way in which a student copes with stress could be a determining factor for how motivated he or she is as a learner as well as his or her academic and clinical performance.

\section{Purpose}

The primary purpose of this study was to understand and describe the ways in which graduate students' learning styles, motivation, stressors, and coping strategies impact clinical development. While some research has been carried out regarding student therapist development, particularly in psychotherapy and education, more research is needed to examine the training experiences for SLP students. Greater insight into the learning and coping processes of students could improve supervision and instructional practices if one considers the student's approach to learning to be the starting point. To understand the learning and coping processes of speech-language pathology students that takes into account the learning processes of millennial students, a qualitative method was chosen. A qualitative approach was chosen to evaluate the experience of graduate training because of the lack of empirical evidence evaluating the phenomenon of interest with SLP students and this method is well suited for developing foundational knowledge. The specific goals of this study were to:

1. develop an understanding of the millennial graduate speech-language pathology students' learning styles, motivation, internal and external stressors, and coping strategies 
2. develop an understanding of how these factors influenced their training and development experiences

\section{Methods}

A qualitative research paradigm was chosen because it is best suited to complete the goals of this study as it allows for understanding to develop on its own without expectations (Patton, 2015). This method enables investigators to capture the stories of those experiencing a phenomenon, take the personal experiences of the participant, and combine them with external events contributing to the topic of interest (Patton, 2015). Therefore, the feelings and experiences of millennial students experiencing a graduate level speech-language pathology program were combined with knowledge about aspects of the program itself to form a theory regarding the training and development of speech-language pathologists.

Research Participants. Both general and specific criteria were used to select the study participants. In general, to be included in this study, the participants had to be able to (1) complete the required questionnaire, (2) adequately communicate about their graduate training experiences, and (3) be willing to fully share their experiences about the phenomenon being explored. Specifically, they also had to be graduate students entering a graduate training program in speechlanguage pathology, over 19 years of age, literate, and monolingual, English speakers. In keeping with a qualitative research design, the number of interviews collected was limited to a small sample. Theoretical sampling was used to provide a varied opportunity for observation of the population of interest. Participants were selected based on their involvement with the phenomena under observation (Creswell, 2007).

The participants in this study included eight females who were beginning a speech-language pathology graduate program of study. The participants were diverse in their undergraduate training, previous clinical experience, and age. Previous clinical experience ranged from having no experience, to having only completed ASHA's mandatory 25 observation hours, to having previous hands-on treatment experience. Participant diversity is ideal as a data developed from a diverse sample is more likely to be inclusive and represent a broader range of experiences (Patton, 2015). The participants were between the ages of 21 and $28(\mathrm{M}=22.37, \mathrm{SD}=2.39)$ at the time of their initial interview (see Table 1). Seven of the participants received their bachelor's degrees in communication disorders, while one received a bachelor's degree that was in an undeclared major.

Interview. All of the interviews for this study were conducted by the second author, who has received training in qualitative interviewing. The students who participated in this study were asked to participate in an interview at the beginning of each semester and following the final semester of a 5 semester graduate training program, resulting in 6 interviews per participant. The interviews did not have a pre-established period and continued until all relevant information needed for the study was obtained. All responses were recorded with a high quality PMD671 Marantz digital recorder (Marantz America, LLC, New Jersey). 
Table 1

Demographic Information

\begin{tabular}{|l|l|l|l|l|l|l|}
\hline Pseudonym & Age & Race & Sex & BCD & $\begin{array}{l}\text { Hours Clinical } \\
\text { Experience }\end{array}$ & Type Clinical Experience \\
\hline Kelly & 28 & W & F & No & 0 & Observation \\
\hline Heather & 21 & W & F & Yes & 2.5 & Treatment \\
\hline Julie & 23 & W & F & Yes & 0 & None \\
\hline Ann & 22 & W & F & Yes & $>50$ & Treatment \\
\hline Mary & 21 & W & F & Yes & 6 & Treatment \\
\hline Susan & 21 & W & F & Yes & 24 & Treatment \\
\hline Maria & 22 & W & F & Yes & 5.5 & Treatment \\
\hline Debra & 21 & W & F & Yes & 4.5 & Treatment \\
\hline
\end{tabular}

BCD (Bachelors communication disorders); W (White); F (Female)

A standard set of administration instructions and interview guidelines were constructed for data collection (see Appendix). The interview guide contained four categories of open-ended questions. The four categories covered general information, clinical questions, academic questions, and supervision questions. Unplanned prompts on topics that required additional elaboration were used when clarification was needed. The research questions outlined in the interview guide were developed to gain an increased understanding of what happens, the emotions experienced, and how students cope as they progress through a graduate SLP program. The goal of the interview was to develop insight into the students' learning style, work ethic, experience in the training process, coping, academic expectations, and supervisory experiences.

Following each of the interviews, the interviewer asked the participant credibility questions to check the researcher's influence on the interview process and to make sure data was thoroughly gathered. First, the interviewer asked if there was anything else that the student felt was important that was not covered. The next two questions pertained to the overall interview experience, including: suggestions for future interviews and if any of the questions were asked in a way that may have influenced the answers provided by the students.

Analysis. The verbal responses obtained during the interviews were transcribed and served as the data source for this study. Pseudonyms were randomly assigned once analysis was complete to more easily discuss each participants' experiences. Glaser and Strauss's (1967) method of grounded theory was used for data analysis because this study aims to develop a theory regarding a relatively unexplored area of speech-language pathology that is based on specific experiences of students in training. Therefore, the data resulted in a theory that was established in data from those who have experienced the phenomena (Glaser \& Strauss, 1967).

The grounded theory method developed by Glaser and Strauss (1967) involves a systematic set of procedures that occurs in stages (Glaser \& Strauss, 1967). First, open coding was used to categorize information. Subcategories were then formed within each category. Next, axial coding was used to assemble the data using a coding paradigm. In this paradigm, the central phenomenon, causal conditions, specific strategies, context, intervening conditions, and consequences were explored and identified. Data acquisition and analysis continued until data saturation was reached. 
Saturation was achieved when the interview data from two participants did not contribute any further to the developing theory or contribute any new themes that would be necessary for understanding the phenomenon of interest (Glaser \& Strauss, 1967). Qualitative Solutions and Research (QSR-N4) software was used to facilitate the organization of the data into a hierarchy of categories (NViVo 10, 2014). The number of participants who contributed meaning units to each of the higher-order categories was tallied to follow the degree of convergence between participants.

Credibility. In qualitative research, objectivity is not the goal given that researchers cannot entirely remove themselves and their biases from a study. Rather, keeping in compliance with a qualitative paradigm, the credibility of the findings will be of significant interest. In this study, credibility was addressed through the incorporation of the following procedures:

1. All interviews were recorded with a high quality digital recorder and transcribed verbatim prior to analysis.

2. Personal and professional biases regarding student training and development were identified before the interviews and were reviewed as themes emerged. Memos were kept to record any emerging hypotheses among developing categories throughout the analysis process. This process involved the researcher writing down ideas about the evolution of the developing theory (Glaser \& Strauss, 1967). Procedural, coding, and theoretical memos were kept throughout the data analysis process (Glaser \& Strauss, 1967).

3. Investigator triangulation was used to incorporate views from multiple sources in order to credibly establish a theme from more than one point of view (Creswell, 2007). Investigators separately coded the meaning units and then employed the constant comparative method to seek consensus (Patton, 2015). Disagreements between the two investigators were handled by privileging the second investigator's perceptions. This was handled in this manner because the second investigator interacted directly with the participants.

\section{Results}

Analysis of the interviews resulted in a hierarchy containing four layers. The student interviews were broken down into 3,792 meaning units, which comprised the lowest layer of the hierarchy. Results of investigator triangulation indicated $90 \%$ reliability between investigators in the determination of the meaning units. The top layer of the hierarchy is the core category, which pulls together the essence of the phenomenon being explored. The core category is comprised of five clusters, which forms the second layer of the hierarchy. The clusters were derived from layer three that contained a total of 23 categories and layer 4 that contained 32 subcategories. In qualitative research, a large amount of data is often accumulated. For that reason, it is common practice for researchers to separate their findings into companion articles or multiple book chapters (e.g., Rennie, 1994a, 1994b). Therefore, this article describes the two clusters that address student coping and learning and focuses on the categories and subcategories therein (see Table 2 for an overview of the clusters, categories and subcategories). 
Table 2

Cluster, Category, Subcategory Information

Cluster 1: To successfully complete graduate training, students have increasing expectations of themselves that are met by putting forth effort into organization, time management, and finding their preferred learning styles.

\begin{tabular}{|c|c|c|c|}
\hline Categories & $\mathrm{n}$ & Subcategories & $\mathrm{n}$ \\
\hline $\begin{array}{l}\text { 1. Effort \& work } \\
\text { ethic }\end{array}$ & 7 & $\begin{array}{l}\text { A: Amount of effort } \\
\text { B: Strong \& stable } \\
\text { work ethic }\end{array}$ & $\begin{array}{l}4 \\
7\end{array}$ \\
\hline $\begin{array}{l}\text { 2. Importance of } \\
\text { Organization }\end{array}$ & 7 & $\begin{array}{l}\text { A: Time } \\
\text { management skills }\end{array}$ & 5 \\
\hline $\begin{array}{l}\text { 3. Self-expectations } \\
\text { versus supervisor } \\
\text { expectations }\end{array}$ & 5 & & \\
\hline $\begin{array}{l}\text { 4. Working \& } \\
\text { learning styles }\end{array}$ & 8 & $\begin{array}{l}\text { A: Hands on \& } \\
\text { visual learning } \\
\text { styles } \\
\text { B: Working \& } \\
\text { Learning Styles } \\
\text { remaining the same }\end{array}$ & 7 \\
\hline $\begin{array}{l}\text { 5. Helpfulness of } \\
\text { undergraduate } \\
\text { coursework }\end{array}$ & 4 & & \\
\hline
\end{tabular}

Cluster 2: Clinician development occurs throughout graduate training and influences many areas of the student's life, including their clinical abilities and their stress levels, causing them to cope using several management strategies

\begin{tabular}{|l|l|l|l|}
\hline $\begin{array}{l}\text { 1. Graduate } \\
\text { students' role as a } \\
\text { therapist }\end{array}$ & 8 & $\begin{array}{l}\text { A. Self-regulation } \\
\text { B. Increasing } \\
\text { flexibility } \\
\text { C. Performance } \\
\text { level } \\
\text { D. Client rapport }\end{array}$ & 8 \\
\hline $\begin{array}{l}\text { 2. Measuring } \\
\text { personal success \& } \\
\text { satisfaction }\end{array}$ & 8 & 8 & 8 \\
\hline $\begin{array}{l}\text { 3. Management of } \\
\text { stressors }\end{array}$ & 8 & $\begin{array}{l}\text { A: Experiencing } \\
\text { stressors } \\
\text { B: Overall } \\
\text { overwhelming } \\
\text { experience } \\
\text { C. Coping with } \\
\text { stress }\end{array}$ & 8 \\
\hline 4. Clinical growth & 4 & I & 8 \\
\hline
\end{tabular}


Cluster 1: To successfully complete graduate training, students have increasing expectations of themselves that are met by putting forth effort into organization, time management, and finding their preferred learning styles. All participants $(\mathrm{N}=8)$ endorsed this cluster that resulted from five categories describing different aspects of the participants' working and specific learning styles. Each of the five categories will be presented (see Table 2).

Category 1: Students mindfully put forth effort while exhibiting a strong work ethic that plateaus after the second semester of graduate training. Seven participants endorsed this category $(n=7)$. Two subcategories emerged that describe the amount of effort and type of work ethic required to progress through a graduate training program.

Amount of Effort. Four participants endorsed the first subcategory (1-1A; $n=4)$. These participants found that a large amount of effort was required to complete graduate training; however, they were only putting forth the amount of effort necessary for completion. Ann stated at the end of her first semester of graduate training, "I do what I think I should, as far as clinic goes. Um, and I put the work in that I think I need to." This amount of effort was stated as becoming increasingly greater across semesters, but was required for managing an increased caseload and for learning the skills necessary to become an effective speech-language pathologist. While the participants did what was necessary to complete the tasks at hand, it was evident that the students strived to be efficient and were very protective of their time.

Strong and Stable Work Ethic. Seven participants endorsed the second subcategory (1-1B; n=7). These participants were found to believe that they possess a strong work ethic that remained strong through the duration of the training program. Heather stated, "I have a very hard work ethic." Other words that participants used to describe their work ethic included: thorough, dependable, and diligent. The participants' work ethic remained the same and did not appear to change after the second semester of graduate training until the end of graduate training. Susan stated, "I mean, I feel like I put just as much into it now, um, as I did before." The remaining participants endorsing this subcategory made similar statements. The participant's work ethic appeared to be predominately extrinsically motivated. That is, it was driven by the desire to be compliant, achieve a specific outcome or avoid the consequence of appearing that they lack competence in a specific area. While the work ethic they displayed was strong, stable and intentional the students often lacked autonomy in the process. They were often performing to satisfy external academic and clinical demands being placed upon them or to demonstrate an ability and maintain a feeling of self-worth.

Category 2: Organization is an important aspect of training that can improve overall success, preparation, and the student's ability to learn (1-2). Seven participants endorsed this category $(n=7)$ and one subcategory $(n=5)$ emerged from the category. These participants found organization to be a key skill or strategy that is necessary to complete a graduate training program. Prior to beginning clinical training, Heather stated, "I'm very organized. I like to be prepared." Prior to the third semester of graduate training, Maria stated:

I mean if anything I have to be even more like, on top of lists and just like in the spring it's just so chaotic. Like I'm pretty organized. I think that's how I - if I wasn't I would absolutely go insane. So...I try to stay organized. 
Consistent with the millennial generation, the students had a strong preference towards staying organized and having structure. Organization was a tool or strategy used by many of the participants throughout graduate training to alleviate the stress of an increased clinical and academic workload. When structure lacked or the students could not prepare in advance it often resulted in increased stress, anxiety and discomfort.

Time Management. The need for successful time management skills increases throughout graduate training and is a difficult skill to learn. Five participants endorsed this subcategory (1$2 \mathrm{~A} ; n=5)$. Time management skills, a form of organization, were found to be an increasing challenge throughout graduate training. At the beginning of graduate training, Debra stated, "It's just more time management than before "cause there's more to be done." Towards the middle of graduate training, Debra also stated, "It was a lot more time management issues this semester than the previous since we had more clients and class demands as well." This indicates an increasing time management requirement. A lack of time management abilities was found to increase levels of stress for the students, while the ability to manage time was found to decrease stress. As indicated earlier, the students were protective of their time and wanted to be efficient. As time or workload demands increased the students appeared to struggle with how to accomplish the tasks at hand in an efficient manner. They coped with the increased demand by trying to personally impose structure and prioritizing certain tasks.

Category 3: When beginning graduate school, self-expectations may be unrealistic and mismatched with client or supervisor expectations; however, as graduate training continues, self-expectations increase with supervisors' expectations (1-3). Five participants endorsed this category $(n=5)$. Throughout graduate training, several participants felt as if their self-expectations were unrealistic. When referring to her self-expectations prior to beginning graduate training, Mary stated, "Course that might be a little too high expectations right now. I don't know." These expectations included clinical performance and abilities. As graduate training continued, selfexpectations were found to increase. At the end of the third semester of graduate training, Kelly stated, "I feel like I'm probably going to expect a lot more of myself, even, and less of my supervisor's input in making judgments and making decisions for me, and really putting it on myself." Self-expectations continued to increase at the end of graduate training and eventually matched the supervisor's expectations for the students, indicating increased self-efficacy.

Category 4: Working and learning styles fluctuate between hands-on and visual styles during the first semester, but plateau at the end of the first semester (1-4). All participants endorsed this category $(\mathrm{N}=8)$. Two subcategories developed during analysis of the participants' responses. The first subcategory (1-4A) focused on the specific types of learning styles the participants used to complete coursework and clinical work. The second subcategory (1-4B) involved the time required for the participants' working and learning styles to solidify and then plateau.

Hands-on and Visual Learning Styles. Students indicated that they preferred using a combination of hands-on and visual learning styles throughout graduate training. Seven participants endorsed this subcategory $(1-4 A ; n=7)$. Prior to the first semester of graduate training, Kelly stated: 
I'm definitely a visual learner. Um...I like to see things, and then I like to write things down. So, I take a lot of notes, and re-copy my notes, and seeing things in action kinda helps me put it all together.

Similarly, prior to beginning clinical training Maria found that she used a combination of both learning styles. She stated, "But I do think like, actually, like, um... working hands-on like with a client, I definitely remember those cases more than... over visual. But like, I know how I learn is visual." This trend continued throughout graduate training. Visually presenting feedback or therapy ideas was found to assist students in internalization of their supervisor's suggestions, while using a hands-on approach to learning allowed students to personally relate to experiences. However, it should be noted that the students also described how they needed concrete experiences to use as the basis for many of their observations, whether it be hands on active experimentation or visual reflective observation. Therefore, while they did indicate a preference to have hands-on or visual learning experiences they preferred them within the context of concrete experience rather than an abstract experience that required greater conceptualization.

Working and Learning Styles Remaining the Same. All participants (1-4B; N=8) endorsed this subcategory. The students all indicated that they maintained a preferred working or learning style throughout the duration of the graduate program. When asked if her learning style had changed during her third semester of graduate training, Kelly stated, "I think I'm still pretty consistent." This indicates that once established, working and learning styles are employed in similar manners during both academic and clinical training. The students do not describe any attempts to adapt or adjust their styles with the different modes of presentation that accompany the different supervision or teaching styles of the faculty.

Category 5: When beginning graduate training, undergraduate academic and/or clinical coursework was found to be a helpful preparation aid (1-5). Four participants $(n=4)$ endorsed this category. Prior to beginning graduate training, undergraduate coursework and clinical work was described as a helpful preparation aid. Julie stated:

I think that I got an outstanding education at XX [university]. And I think that what I've learned so far has been a lot of review, and, maybe not necessarily review for everyone else. But definitely review for myself. Um...I think that I came very prepared from my undergraduate [program].

This preparation enabled Julie to begin graduate training with a level of confidence that other students may not have experienced. Not all students begin graduate training in speech-language pathology with a background in communication disorders; therefore, their feelings of preparedness may differ from students with an undergraduate background in a field other than communication disorders. For example, when discussing students whose undergraduate coursework was in a different field of study, Susan stated:

Well several of them, [students with other backgrounds], you know, just, I guess they're starting in grad school so they've had to observe. And so they have one client now, but they're not familiar, or, as much so familiar with the objectives and procedures and how, um, a clinic functions. 
This indicates that some students may enter graduate training better equipped to begin clinical work at the beginning due to their academic preparation and previous experience with clinical procedures. Different degrees of experience and clinical exposure during undergraduate training influenced the students' comfort level and confidence. It also influences student stress level and places increased demand on those students without background compared to those who do come into a program having background.

Cluster 2: Clinician development occurs throughout graduate training and influences many areas of the student's life, including their clinical abilities and their stress levels, causing them to cope using several management strategies. All participants $(\mathrm{N}=8)$ endorsed this cluster resulting in four categories (see Table 2). The first category describes the students' view of their new role of a clinician. It resulted in five subcategories. The second category discusses the participants' view of how they measured personal success and satisfaction throughout graduate training. The third category discusses the participants' experiences with stress during graduate training and their coping strategies. The fourth and final category describes the participants' view of their clinical growth once graduate training has been completed.

Category 1: Graduate students' role as a therapist throughout training increased from completion of simple therapeutic tasks to complex tasks including their ability to be flexible and develop rapport with clients $(2-1)$. All participants $(\mathrm{N}=8)$ endorsed this category, which resulted in four subcategories. These subcategories discussed the students' overall thoughts on their clinical abilities, development of flexibility, development of client rapport, as well as overall clinical performance level. Many students found that they were able to complete clinical tasks when beginning clinical training; however, they were able to successfully complete more complex tasks as graduate training progressed. Overall abilities also increased as clinical experience continued to occur.

Self-regulation of clinical abilities. Clinical abilities and responsibilities transitioned from concrete, externally directed and technical to somewhat internally directed, more flexible, and skilled during clinical training. All participants $(2-1 \mathrm{~A} ; \mathrm{N}=8)$ endorsed this subcategory. Participants felt that they were accountable for completing simpler activities towards the beginning of clinical training, such as: preparation, basic planning, and implementation of goals. For example, when asked what she was responsible for, Ann stated, "You know taking basic data." As graduate training progressed, responsibilities increased in complexity. For example, when discussing her clinical abilities towards the middle of graduate training, Mary stated, "But as far as maybe coming up with ideas, being able to sort of lay out like a plan, a therapy plan. I feel like that should be more, I'm, I should be able to do that without them saying, you know, 'These are the steps, this is what you have to do."'

In the third and fourth semesters of graduate training, students identified higher-level skills that they were able to competently complete such as behavior management, clinical problem solving, and the ability to consider multiple perspectives when working with clients. For example, when asked what she was responsible for during her fifth semester of training, Heather stated, "It's my responsibility to provide [patients] with the opportunity to improve by what we do and what we work on." She began to take ownership of the therapeutic process. Other responsibilities included: 
evaluating clients and choosing their treatment objectives, assessment selection and administration, and independent completion of clinical work.

Increased flexibility. Graduate students experienced increased flexibility throughout graduate training, which was identified as a necessary, but a difficult clinical skill to acquire. All participants $(2-1 \mathrm{~B} ; \mathrm{N}=8)$ endorsed this subcategory. The participants repeatedly discussed the importance of flexibility, how difficult it is to develop flexibility, and the increasing amount of flexibility they possessed. After the first semester of graduate training, students were still experiencing difficulty being flexible during therapy sessions. For example, Ann stated, "And I also don't know how to write data when I'm being flexible. Because if I said I was going in and using my objectives and then I change in the session, which I do, then - then the supervisors are like 'what is the data?' And I'm like "well..." After the third semester of graduate training, many students mentioned that they were experiencing growth in the area of flexibility. For example, Debra stated, "and just being flexible with what I'm doing in therapy and changing [with] the needs of the clients. Which I grew a lot in this semester, but I think there [is] still room for growth there." Overall, flexibility was found to be an important skill that was viewed as necessary but the participants described how difficult it was to develop. It required that the students recognize that everything could not be as organized and planned as they would like for it to be. That is, the participants began to recognize that they would have to be able to, despite sometimes having what they perceived to be the best plan, respond in the moment to a change in client needs or general academic demands. There was an increase in the students' ability to be flexible within a session as they progressed throughout graduate training.

Graduate student performance. All of the participants indicated that they were performing well as therapists by the end of their second semester of graduate training $(2-1 \mathrm{D} ; \mathrm{N}=8)$. At the beginning of graduate training participants did not feel as if they were performing adequately. As graduate training progressed into their second semester, students were found to think that they were performing well as a therapist during clinical work. During the beginning of graduate training, participants felt most comfortable with the procedural nature of clinical work. For example, Marie stated, "I am comfortable with the therapy session," after completion of the first semester of graduate training. As clinical training progressed, the participants' comfort level with higher-level tasks increased. For example, Ann stated, "I feel like I could give resonant voice therapy comfortably by myself now." Comfort level was found to decrease when clinicians began working with unfamiliar populations at unfamiliar clinical practicum sites. Confidence was found to increase throughout graduate training as experience increased. Once graduate training was complete, for example, Kelly stated:

I feel like now I've graduated, got a degree, got the books, and then you know, at home that I can go back to and I feel you know, maybe I don't remember everything, but I feel pretty confident that I can go back and find what I need when I need it.

This indicates the increase in confidence that occurred, when faced with clinical problem solving opportunities, even if the students aren't able to recall all of the information they were provided during graduate training. Though independence was found to increase, it was not found to be as complete as stated by the students. Participants still found that they depended on their supervisor at some level. For example, when Ann was asked how independently she felt that she was 
performing, she stated, "Ninety percent." Most students agreed that they were performing at an almost completely independent level by the time graduate training was complete; however, they did not believe they were completely independent clinicians indicating that they still desired a level of support from their clinical fellowship supervisor.

Client rapport. All participants were able to identify their ability to connect with their clients by the end of their fourth semester of graduate training. All participants $(2-1 \mathrm{C} ; \mathrm{N}=8)$ endorsed this subcategory. Towards the beginning of graduate training, participants described their relationships with their clients as "improving." This appeared to have been influenced by the students' focus on the procedural and skill-based aspects of the therapy session. By the end of their fourth semester of clinical training, all participants found that they were able to identify and connect with their clients. For example, when Julie was asked if she was able to connect with her clients, she stated, "I think so. As far as connecting with them as a person, yes." This occurred during her fourth semester of graduate training, similar to other students. It appears that the students have to develop some expertise with the logistical and technical components of the therapeutic process before they can engage in a meaningful therapeutic relationship with their clients.

Category 2: Personal success and satisfaction was found to be client-dependent at times and was measured through progress, feedback, faculty approval, academic achievement, and personal feelings and/or effort (2-2). All participants $(\mathrm{N}=8)$ endorsed this category. Participants discussed several factors that contributed to their feelings of personal success and satisfaction. Towards the beginning of graduate training, these feelings were dependent on grades and faculty feedback. Feeling successful was externally driven and based on external reinforcements. For example, Julie stated, "I think that I was probably successful going into it, I just didn't feel that way. And so, to like have feedback from them um... was helpful I guess I would say." As graduate training continued, measures of personal satisfaction were client dependent. This clientdependence was documented through the client's response to the clinician as well as their progress. At the end of graduate training, half of the participants found that they felt successful, due to personal feelings of effort, rather than depending on outside sources of success as indicators. They no longer needed an external source of approval to feel as if they had been clinically successful because they could now personally gauge their successes, or lack thereof.

Category 3: The overwhelming nature of graduate training caused students to manage both internal and external pressures by requesting and receiving advice from academic and clinical faculty and completing their required schoolwork prior to the due date (2-3). All participants $(\mathrm{N}=8)$ endorsed this category resulting in three subcategories. They discussed the pressures that resulted in stress experienced during graduate training, the overwhelming nature of graduate school, and stress management techniques employed to decrease stress levels.

Internal and external stressors. Graduate students experienced both internal and external pressures throughout training resulting in stress regarding their new expectations $(2-3 \mathrm{~A}, \mathrm{~N}=8)$. Much stress and anxiety was experienced throughout graduate training, and was expressed by the students as they experienced cognitive and affective stress. Some of the affective stress experienced included increased levels of emotion surrounding their performance or ability to complete tasks successfully. For example, Susan stated, "I felt like there was a constant pressure to do my best." The students appeared to stay in a heightened emotional state throughout the 
duration of the program. The type of emotion experienced varied some from student to student but the emotions were generally negative and associated with fear of failure, anxiety around performance, frustration, anger, or fatigue. External stressors were also documented. For example, Kelly stated, "There was a little bit of pressure from my supervisor." Other external stressors resulted from: expectations to complete clinical work in a timely manner, preparation required for working with unfamiliar client populations, and general performance expectations from both academic faculty and clinic supervisors.

Overwhelming Experience. Graduate training was overall found to be an overwhelming experience for students that decreased with time and experience $(2-3 B, n=7)$. The majority of the statements made regarding the overwhelming nature of graduate training occurred between the first and third semester. At the beginning of graduate training, Maria stated, "Um, well, actually I've been really overwhelmed, to be honest." Many similar statements were made during this time in the students' training. Towards the end of graduate training the tone of the nature of graduate training changed. Heather stated, "So I couldn't imagine my first semester feeling comfortable with you know, doing therapy for 45 kids, we start out slow, but I mean, I really enjoyed my internship I didn't feel overwhelmed or really stressed out about it, so I think that shows the growth." Other students experienced similar feelings towards the end of graduate training.

Coping with stress. Since graduate training increased the levels of stress in many graduate students, they had to find ways to manage both the internal and external stresses they were experiencing. Graduate students managed stress and the associated emotions through consultation with academic and clinical faculty members and completing required schoolwork (2-3C, N=8). In regards to this type of stress management, Susan stated, "I mean, talking to my supervisors helps a lot, too, if I feel like I'm struggling." Completing required schoolwork was found to be a way that many students coped with the stress they were experiencing. Many students prioritized the work that needed to be completed and described how they had to sacrifice free time to work on school obligations. This decision resulted in decreased stress during graduate training. It was evident that the students sought out support, tried to provide structure to their daily experiences, and used time management strategies to cope with the stress they were experiencing during graduate training.

Category 4: Clinical growth occurred throughout graduate training due to many academic as well as clinical factors including knowledge gained and experience within the clinical environment (2-4). Four participants $(n=4)$ endorsed this category, which resulted in a discussion of the general occurrence of clinical growth and the causes of it. This discussion did not occur until the last semester of graduate training due to the nature of the question posed. Four participants returned for the final interview post-graduation and agreed that they experienced clinical growth throughout graduate training. Many factors contributed to this growth including academic and clinical factors. When discussing the factors contributing to clinical growth, Ann stated, "That's been sort of just accumulation of knowledge through clinic and classes and everything else." The other three participants made similar statements regarding the factors contributing to their clinical growth. It was also at the end of their graduate training that the students really began to recognize that they were going to need to become more flexible and internally self-regulated as well as intrinsically motivated with regards to clinical learning. 
Core Category: Undergraduate and graduate coursework prepares students to overcome clinical challenges and experience clinical growth by transcending stress to become more internally regulated and intrinsically motivated learners. The five clusters that resulted from an analysis of all of the data were combined and used to derive a core category, the highest hierarchical layer, which describes the overall clinical development process. Students experienced many aspects of graduate training that impacted clinical development. Although the core category resulted from identifying common themes across the five total clusters, the relationship between the first and second clusters presented and the core category is emphasized in this article. The remaining three clusters are presented in a companion paper (see Rapillard, Plexico, \& Plumb, (2019) for a complete description of the project findings). These experiences were thought to have molded aspects of the clinician's performance such as how they performed therapy and what they expected from themselves and those in their academic program.

The core category describes how the three major factors were found to influence clinical development and included: academic coursework, clinical experiences, and supervisory experiences. Academic coursework was discussed as a means to prepare students for clinical work but was not identified as a factor that could completely prepare a clinician for future clinical problems. The academic component of the program provided students the opportunity to think and reflect through more abstract conceptualization. Clinical experiences were viewed as foundational to student clinical growth. Clinical education was more in line with what the students desired in terms of a learning experience. Clinical education was more concrete and the participants could readily engage in reflective observation or active experimentation, which coincided with their preferred visual and hands on learning styles. As the participants progressed through the program they moved from being predominately extrinsically regulated to an integrated regulated style. The graduate student training experience was found to be a stressful or overwhelming experience. Students struggle to impose order, preserve time and be efficient with increasing demands. Coping strategies used by students influenced clinical abilities and the student's feelings of self-efficacy throughout training. Stress was predominately managed using time management and support based strategies. Over the course of graduate training the students' locus of causality shifted from being external where they were seeking compliance, reinforcement and trying to avoid external or internal repercussions to being more internally regulated where they were beginning to personally see the value and importance of the material they were learning.

\section{Discussion}

Analysis of the forty-four interview transcripts resulted in an understanding of graduate student therapist development that incorporates aspects of student motivation, learning style, as well as coping on the academic and clinical learning process. Since clinical development is an understudied topic in the field of speech-language pathology, grounded theory was used to develop an understanding of clinical development based on the experiences of eight graduate students in speech-language pathology. The following section discusses the study's results in relation to learning and motivation theory.

Millennial Student Learning Styles. The participants discussed their preferred learning styles during the first three semesters of graduate training. They described their preferred style as a combination of hands-on and visual; which easily aligns with portions of David Kolb's experiential 
learning cycle (2004). The students preferred to take in information using CE. The students did not identify AC as a preferred way of taking in novel or new information. The preferred hands-on and visual learning styles, expressed by the students, coincides most directly with the RO and AE portions of the cycle. The participants preferred to have hands-on involvement with clinical work, while also having opportunity to visually observe supervisors to learn. Hands-on clinical experience provided trial-and-error experiences and supervisor feedback provided information for personal reflection. Students expressed interest in academic professors providing practical application opportunities within the classroom that would more closely match the kind of learning experiences they are provided in the clinic. Students did not prefer using AC as a way of gaining novel information, which would have been similar to an assimilator way of thinking. The participants predominately used a more accommodating or diverging style of learning. The students appeared to value experiencing, imagining and reflecting styles of learning where they found meaning from more involvement in the learning experience.

Learning preferences discussed by these millennial participants also coincided with generational learning differences. They expressed interest in practical and concrete knowledge. They were less interested in learning the theoretical basis for the methods that they were employing, which may be due to the more abstract conceptual nature of this information. The students also expressed a desire to be told of their supervisor's expectations. This is similar to the structure-craving, rulebased nature of students who are a part of the millennial generation. Roberts, Newman, and Schwartzstein (2012) suggest that instructors provide context as well opportunities for application of novel information since simple answers to many questions can be simply found on the internet. Incorporation of technology in the classroom is also thought to increase learning experiences, when considering the millennial learner, since technology is a pervasive part of everyday life for this generation.

The millennial students' position as predominately accommodating learners who prefer experiencing, imagining, and reflecting defines their general learning region and reflects their learning space. Clinical supervisors and academic faculty can adjust to this style of learning by creating a learning space that will promote optimal student growth and assist students in the learning process given their learning style. For example, providing practical and concrete ways that theoretical information can be clinically applied may increase the likelihood that millennial students will find the more abstract portions of the coursework to be relevant. Most graduate programs place emphasis impressing information on the learner in the classroom or during supervisor meetings rather than giving students the opportunity to test or express what they know or have learned. As educators we need to give learners the space they need to take charge of their own learning, but at the same time give that learning space enough structure for the millennial student to progress through it. Students can be encouraged to construct knowledge on their own when give parameters or guidelines rather than being passive recipients of knowledge from others. There is often an emphasis on thinking instead of acting. There is also often an emphasis on thinking over feeling in the educational experience. Positive emotions can facilitate learning; whereas, negative emotions like fear and anxiety can decrease student motivation and interest in the material to be learned (Damasio, 2003).

Student Motivation. The students progressing through a graduate program are active and interested in being successful. Overall, they are motivated. Organismic integration theory (OIT), 
a portion of the self-determination theory, can be applied to the development of student speechlanguage pathologists when discussing how they are motivated, what drives student learning and the ways in which students measure personal success. During the first through third semesters of training, students identified introjected regulation as the contributor to feelings of personal success. These regulators included grades, supervisor feedback, and supervisor approval of decisions as a means of motivation. As graduate school progressed, students moved through identified regulation. This occurred from the first to the fifth semesters of graduate training and included regulators that were client dependent such as their progress and rapport. During the fourth and fifth semesters of graduate training, four of the five participants experienced integrated regulation when describing their feelings of personal success. These students felt successful internally and were not relying predominately on outside sources or the need to avoid the feeling of disapproval from others.

As students progress through the different levels of regulation, the students begin to cycle between identified and integrated regulation. As a student, or new professional speech-language pathologist, clients with unfamiliar disorders or difficulties require differing types of regulation that change as the clinician's confidence and comfort level with diagnostics and treatment increase. For example, when providing services to a client with an unfamiliar disorder, a clinician may rely on the client's response to treatment and their therapeutic relationship until a comfort level and understanding is reached with the desired treatment approach. In other words, as a novice clinician is developing into an experienced clinician, efficacy expectations increase. This indicates the clinician's increasing acknowledgement that his or her specific behaviors cause a desired outcome, which in this case is client progress.

Supervisors can use this information in combination with application of the learning style discussed previously when providing clinical learning opportunities. Application of the progression of regulation may lead to insight regarding what the clinician needs from the supervisor to become an effective, independent clinician. Internal and external facets of motivation determine a student's locus of control, which indicates the importance of consideration of motivation during student clinical development.

Coping with Graduate School. Participants identified many stressors experienced during all five semesters of graduate training as well as methods of coping due to its overwhelming nature. Internal stressors, such as self-expectations, as well as external stressors, such as time management, the need to be flexible, and increasing faculty expectations, were experienced throughout graduate training. These were managed through a combination of emotion-based and problem-based coping strategies. The most widely used form of emotion-based coping that was documented included seeking social support from faculty members and peers, while the most widely used form of problem-based coping included completion of work ahead of time. Academic professors as well as clinical faculty should consider levels of stress experienced as well as coping strategies used. It was evident that the students feel overwhelmed and stressed as they progress through a graduate training program.

Overwhelming feelings, and in some instances anxiety, indicates the need for increased support. As students increase their self-efficacy, progress through the graduate training, and feel they are more in control of their success support can likely be lessened. In the interim, faculty members are 
in a unique position to help graduate students successfully cope with the stressors experienced during graduate training. To support coping abilities, supervisors and faculty should make efforts to openly discuss the possible common stressors (both internal and external) associated with graduate study in speech-language pathology. These discussions may include topics such as expectations related to clinical work/deadlines, working with new client populations, and the evaluation process. In addition, support services should be explored, such as mentorship by faculty or peers (e.g., pairing a first year student with a second year student).

Open dialogue with students in times when they are overwhelmed is also recommended. Through this dialogue, learning curves/trajectories may be discussed so that they better understand that as they gain experience, these feelings should decrease. Finally, because the participants reported that completing required school work prior to due dates was a successful coping strategy, programs may wish to offer instruction on topics relevant to time management. Backward mapping could be one such topic to ensure students will be able to complete required schoolwork in a timely and efficient manner. The students were also coping with how to become more flexible while trying to maintain a sense of structure that coincides with their desire for rule and order. Clinical scaffolding of expectations would also allow students to independently complete clinical tasks while still feeling as if rules are still in place to provide them with the structure they need. Using this method may allow students to move from expert-level scaffolding to self-scaffolding, as easily as possible, thus lessening the pressures of self- as well as supervisor expectations. During this process the student and supervisor would need to explore what degrees of freedom or adjustments a client might need in a session. Self-scaffolding occurs when the student is able to realize where his or her level of knowledge begins to require problem solving to obtain unknown information that assists in task completion (Venne \& Coleman, 2010).

\section{Strengths, Limitations, \& Future Research Directions}

The primary strength of this study includes the depth and breadth of the information gathered by the participants. Information on student learning styles, coping, and motivation were all considered within the context of the lived graduate training experience. This information is foundational and gives supervisors and faculty insight into the student experience and how they can best support graduate students professional development. Another strength is the design of the research. The research design allowed for individualized understanding of the clinical development process. Each cluster also reached saturation due to the ample amounts of experiences presented by the students regardless of individual differences in background. Finally, credibility checks were also employed, which increased confidence in the findings presented.

A number of limitations should be considered during interpretation of results of this study. First, it should be noted that clinical development is an individual process and cannot be generalized to each student in the same fashion. For example, students may enter graduate training with different learning styles, prior experiences, and differing bases of knowledge. Second, the students in this study were experiencing training in a single graduate training program, and participants were limited to one race, gender, and language. ASHA has particular requirements for accredited university programs; however, each program differs in various ways, which may influence their students' overall experience and clinical development. Finally, a definition of "successful clinical development" is ambiguous at this time, and therefore, could not be applied to the final 
performance of these therapists. Future research should aim to provide information gained from longitudinal studies documenting students' progression through a clinical learning model with particular consideration of learning styles, stress, and coping strategies employed by students and the impact those factors have on learning outcomes and therapeutic abilities and outcomes.

\section{References}

American Speech-Language-Hearing Association. (2015). Planning your education in CSD [Webpage]. Retrieved from http://www.asha.org/Students/Planning-Your-Education-in$\mathrm{CSD} / \#$ graduateprogram

Brackney, B. E., \& Karabenick, S. A. (1995). Psychopathology and academic performance: The role of motivation and learning strategies. Journal of Counseling Psychology, 42(4), 456.

Coburn, D., \& Jovaisas, A. V. (1975). Perceived sources of stress among first-year medical students. Journal of Medical Education, 50(6), 589-595.

Creswell, J. W. (2007). Qualitative inquiry \& research design: Choosing among five approaches. Thousand Oaks, CA: Sage Publications, Inc.

Damasio, A. (2003). Feelings of emotion and the self. Annals of the New York Academy of Sciences, 1001(1), 253-261.

Deci, E. L., \& Ryan, R. M. (1985). Intrinsic motivation and self-determination in human behavior. New York, NY: Plenum.

Dyrbye, L. N., Thomas, M. R., \& Shanafelt, T. D. (2005). Medical student distress: causes, consequences, and proposed solutions. Mayo Clinic Proceedings, 80(12), 1613-1622.

Glaser, B., \& Strauss, A. (1967). Discovery of grounded theory. Chicago, IL: Aldine.

Heins, M., Fahey, S. N., \& Leiden L. (1984). Perceived stress in medical, law, and graduate students. Journal of Medical Education, 59(3), 169-179.

Howe, N., \& Strauss, W. (2000). Millennials rising: The next great generation. New York, NY: Vintage.

Hudson, S. A., \& O’Regan, J. (1994). Stress and the graduate psychology student. Journal of Clinical Psychology, 50(6), 973-977.

Kolb, D. (2004). Learning styles inventory. In Lowy, A. \& Hood, P. (Eds.), The power of the $2 x$ 2 matrix: Using $2 \times 2$ thinking to solve business problems and make better decisions (pp. 267-271). San Francisco, CA: John Wiley \& Sons.

Kolb, A. Y., \& Kolb, D. A. (2005). Learning styles and learning spaces: Enhancing experiential learning in higher education. Academy of management learning \& education, 4(2), 193212.

Lancaster, L.C., \& Stillman, D. (2002). When generations collide. New York, NY: Hamer Collins.

Lazarus, R. S., \& Folkman, S. (1984). Stress, appraisal, and coping. New York, NY: Springer Publishing Company, Inc.

McCasland, M. (2005). Mobile marketing to millennials. Young Consumers, 6(3), 8-13.

Miller, L. H., Smith, A. D., \& Rothstein, L. (1993). The stress solution: An action plan to manage the stress in your life. New York, NY: Pocket Books.

NVivo qualitative data analysis software (Version 10) [Computer software]. Melbourne, Australia: QSR International.

Patton, M. Q. (2015). Qualitative research \& evaluation methods: Integrating theory and practice (4th ed.). Thousand Oaks, CA: SAGE Publication, Inc.

Rapillard, S., Plexico, L., \& Plumb, A. M. (2019). The influence of supervision and clinical 
experiences on professional development of graduate speech-language pathology students. Teaching and Learning in Communication Sciences and Disorders, 3(1). Retrieved from tlcsdjournal.com.

Reeve, J. (2002). Self-determination theory applied to educational settings. In E. L. Deci \& R. M. Ryan (Eds.), Handbook of self-determination research (pp. 183-203). Rochester, NY: University of Rochester Press.

Rennie, D. L. (1994a). Clients' accounts of resistance: A qualitative analysis. Canadian Journal of Counseling, 28, 43-57.

Rennie, D. L. (1994b). Client's deference in psychotherapy. Journal of Counseling Psychology, $41,427-437$.

Roberts, D. H., Newman, L. R., \& Schwartzstein, R. M. (2012). Twelve tips for facilitative millennials' learning. Medical Teacher, 34(4), 274-278.

Ryan, R. M., \& Deci, E. L. (2000). Self-determination theory and the facilitation of intrinsic motivation, social development, and well-being. American Psychologist, 55(1), 68.

Selye, H. (1956). The stress of life. New York, NY: McGraw-Hill.

Short, E. J., \& Weissberg-Benchell, J. A. (1989). The triple alliance for learning: Cognition, metacognition, and motivation. In C.B McCormick, G.E. Miller, \& M. Pressley (Eds.), Cognitive strategy research (pp. 33-63). Springer, New York.

ten Cate, O. T. J., Kusurkar, R. A., \& Williams, G. C. (2011). How self-determination theory can assist our understanding of the teaching and learning processes in medical education. AMEE guide No. 59. Medical teacher, 33(12), 961-973.

Turesky, E. F., \& Gallagher, D. (2011). Know thyself: Coaching for leadership using Kolb's experiential learning theory. The Coaching Psychologist, 7(1), 5-14.

Venne, V. L. \& Coleman, D. (2010). Training the millennial learner through experiential evolutionary scaffolding: Implications for clinical supervision in graduate education programs. Journal of Genetic Counseling, 19(6), 554-569. doi: 10.1007/s10897-010-93198

Vermunt, J. D. (1996). Metacognitive, cognitive and affective aspects of learning styles and strategies: A phenomenographic analysis. Higher education, 31(1), 25-50. 


\section{Appendix: Interview Questions}

\section{Interview on Training and Development}

In our interview, I will be asking you about your experiences as a student in a speech-pathology training program. I am interested in your experience and how your experiences have influenced you. I am not beginning this interview with expectations of what your answers will be, and am really interested in your own experience and what your training experiences have meant in your own life. To the extent possible I would prefer that you not mention specific client or supervisor names in our discussion. It is appropriate and I encourage you to think about the interactions you have had with specific supervisors and clients, but when you describe those experiences and interactions I would prefer that you exclude his or her name.

The overarching question of this interview is: What is your experience of being a student in a clinical training program?

The interview questions are as follows:

\section{GENERAL INFORMATION}

1) How would you describe your general working and learning style?

2) How would you describe your work ethic?

3) How do you measure personal success and satisfaction?

\section{CLINICAL}

1) What types of things do you do and experience as a student in the training program in Speech-Language Pathology?

a) How do you currently view your role as a clinician at this point in your training and development?

i) Probe: Feelings about the therapeutic process in terms of skills and abilities?

ii) Probe: Accountability in terms of independence for skills at this point in training?

iii) Probe: How they view their performance as a therapist?

iv) Probe: What pressures, if any, are you experiencing at this point in your training and development?

(1) How are you currently managing those pressures?

v) Probe: Comfort level in the role as a therapist?

vi) Probe: Broadly speaking, what factors do you feel contribute to successful therapeutic outcomes?

vii) Probe: How do you feel about working with your clients this semester?

(1) Do you feel you were able to connect with and identify with your clients this semester?

(2) Were your clients able to meet your expectations in terms of their behavior and progress?

(3) Are there some clients you feel better about than others?

b) Describe how you feel about the process of preparing for a session?

c) How do you feel about therapy vs evaluations in terms of your ability and level of comfort? 
d) Have you faced any challenges this semester in your training and development as a therapist?

\section{SUPERVISION}

2) What are your current expectations and needs from your supervisors as a student in the semester of a clinical training program in Speech-Language Pathology?

a) What would be perceived as helpful from your supervisors at this point in your training?

b) What would be perceived as unhelpful from your supervisors at this point in your training?

c) How do you feel about getting feedback?

i) Probe for feedback preference, timing and whether it was perceived as adequate?

d) Did you experience any personal or clinical conflicts with your supervisors this semester?

e) Do you feel your supervisors' expectations of you were reasonable at this point in your training?

f) Do you feel you are receiving an appropriate amount of independence from your supervisor?

g) Please describe any general feelings you have had regarding your supervisory experience thus far.

\section{ACADEMIC}

3) What are your current expectations and needs from the academic faculty as a student in the semester of a clinical training program in Speech-Language Pathology?

a) What role do you feel your academic courses play in your clinical training and development?

b) Please describe any general feelings you have had regarding your academic experience thus far. 